\title{
ENTREVISTA
}

\section{MARIO CAU: \\ PROFESSOR, QUADRINHISTA E ILUSTRADOR}

\author{
Gleica Helena Sampaio Machado Macedo ${ }^{1}$
}

São inúmeras as publicações de recriações em quadrinhos de obras literárias, sobretudo de autores bastante reconhecidos na literatura brasileira. Mas a adaptação de Dom Casmurro, de Machado de Assis, produzida por Mario Cau (desenhista) e Felipe Greco (roteirista), publicada pela editora Devir em 2012, chama a atenção do leitor por sua riqueza nos detalhes, distribuídos em 232 páginas.

As narrativas de Machado de Assis tiveram grande repercussão no século XIX, e ainda hoje são obras muito conhecidas pelo público leitor. Como você encarou essa proposta de recriar uma obra do Velho Bruxo, através do gênero narrativo contemporâneo, História em Quadrinhos?

Foi um grande desafio. Quando fui convidado para participar desse projeto, lá em 2008, fiquei receoso pois até então só tinha trabalhado em HQs curtas. Com o projeto inicial, eu desenharia um capítulo (dos 5 totais), com cerca de 30 páginas. Conforme o projeto evoluiu, os outros artistas inicialmente envolvidos saíram e eu assumi toda a arte, começando do zero para poder ter mais controle sobre a narrativa, composição e design de personagens.

Foi um desafio que se espalhou por 5 anos, pelo menos, onde eu desenhava Dom Casmurro entre outros projetos e minha evolução como artista era aparente, pelo menos para mim.

Eu sempre soube da escala da coisa. Uma adaptação de uma obra literária importantíssima para uma linguagem considerada por muitos

\footnotetext{
${ }^{1}$ Mestranda do programa de pós-graduação em Crítica Cultural, na Universidade do Estado da Bahia UNEB, Campus II. Endereço eletrônico: estudante.gleica@hotmail.com
} 
(especialmente acadêmicos) como "menor". Mas como não tínhamos um limite de páginas nem um prazo apertado, me senti à vontade para fazer do meu jeito. Tive total apoio do Felipe nesse sentido.

E uma coisa que também nos fortaleceu foi a ideia de que sempre que se adapta uma obra para outra linguagem vai existir um ruído, uma interferência de escolhas dos autores. É impossível adaptar algo sem que haja alguma mudança, mesmo que você seja muito fiel ao original. No nosso caso, temos a noção de que nosso livro é o Dom Casmurro de Machado de Assis, adaptado por Mario e Felipe, e não a obra original.

A Narrativa é feita pelo próprio Bentinho, ou Dom Casmurro, é da perspectiva dele que se narra os fatos. Ao traduzir isso para os desenhos, creio que implica do artista uma apropriação desse olhar, qual o maior desafio disso?

Sim, uma das grandes coisas que aprendi com Dom Casmurro foi que a história toda é narrada pelo Bento. Tudo que sabemos sobre esses fatos que ele narra passaram por um filtro dele, e obviamente, ele escolhe o que e como nós vamos saber destes fatos. Então, penso que o que vemos, nas ilustrações, são a visão do Bento das coisas. Isso implica, para mim, em submergir mais e mais no personagem e conhece-lo a fundo, tentar entendelo. Não necessariamente concordar com ele, mas entender o que pensa e o que sente, de onde vêm sua construção psicológica.

Paulo Ramos afirma no prefácio da adaptação que o processo criativo, entre concepção e publicação, durou cerca de seis anos. Como se deu esse processo de tradução da obra machadiana para os quadrinhos? $\mathrm{E}$ em meio a esse processo, como se deu a interação entre desenhista e roteirista? 
Foi um processo bem tranquilo, no geral. O projeto começou de um jeito e terminou de outro: inicialmente era um projeto de uma editora, que convidou o Felipe para adaptar o texto e seria ilustrado por três artistas. Um deles saiu, eu entrei. A editora abandonou o projeto, os outros dois artistas também. Sobramos eu, o Felipe e o roteiro dele, que já estava praticamente pronto em 2009. Em janeiro daquele ano, decidimos que eu faria toda a arte (em vez de abandonarmos, também, o projeto). Já tinha sido uma jornada intensa para o Felipe, que nunca tinha gostado do livro e descobriu, neste desafio da adaptação, um olhar que lhe agradasse. Aliás, eu já gostava do livro, mas foi graças ao roteiro e aos insights do Felipe que eu realmente descobri todo o poder dessa história e dos personagens.

Nós sempre conversamos, mas mais por e-mail e telefone, e nos vimos ao vivo poucas vezes nestes 6 anos. Mas preciso sempre agradecer ao Felipe, por ter confiado em mim e permitido que eu, assim como ele, tivesse total liberdade na produção. Ele fez uma pesquisa incrível de referências visuais e eu me senti bastante confiante para produzir.

O processo criativo foi muito similar a qualquer texto para HQs, eu acredito. Nosso prazo só apertou quando fomos contemplados com o ProAC em 2011, e aí de fato tínhamos uma data para entregar o livro. Entre altos e baixos com editora, conseguimos chegar lá.

As cores também são elementos fundamentais na compreensão dos sentidos produzidos na narrativa em quadrinhos. Por que a predominância do preto e branco na obra?

Geralmente uma HQ é produzida em preto e branco por questões de custo e/ou definição da equipe criativa. Optamos pelo PB em nossa adaptação para evocar o clima noir que o Felipe inseriu na adaptação. Sabemos que é uma história de drama e ciúmes. Sabemos que os desdobramentos dela são pesados, e as cores não só levariam muito mais tempo para serem feitas, como também roubariam um bom tanto dessa compreensão dramática que queríamos para o livro. 
Ao adentrar numa nova mídia, os personagens antes apenas descritos por Machado de Assis, ganham traços e expressões. Como se dá o processo de composição dos personagens?

Costumo comparar meu trabalho com o de um diretor de cinema. Na verdade, o trabalho do quadrinhista compreende várias funções que têm ligação com os filmes. Eu preciso dirigir, fotografar, iluminar, captar a atuação dos personagens... E com isso, preciso criar um elenco que funcione para mim. Como mencionei antes, assim que assumi a produção de toda a graphic novel, decidi mudar muitos "atores" que, para o meu olhar, não funcionavam. É preciso compor esses personagens com feições, expressões faciais e corporais, vestuário que sejam coerentes à suas personalidades e à época. Segui muito do instinto. Por exemplo, José Dias sempre teve para mim um quê de Dom Quixote, e por isso ele tem feições que lembram o personagem de Cervantes. É preciso encontrar o "ator" certo e com ele, saber "atuar" bem nas páginas. Acho que pelo meu tipo de trabalho em quadrinhos, sempre focados nos personagens e na sua complexidade psicológica e na atuação dramática, Dom Casmurro era uma obra que se encaixou muito bem para mim.

E Capitu? "Olhos de ressaca" "cigana oblíqua e dissimulada", como compor essa personagem tão envolvente? Houve alguma inspiração em alguma personagem da vida real?

Capitu é vista pelos olhos do Bento, então ela é belíssima e tem toda uma expressividade no olhar e corpo que remete a algo felino mas de certa forma ingênuo... Ela tem a dissimulação, mas seria isso mesmo? Ou seria o Bento querendo nos convencer de que ela sempre fora dissimulada? Eu adoro a Capitu. É uma personagem incrível, uma mulher forte, moderna, expressiva que vai gradualmente sumindo sob a personalidade cada vez maior e mais confiante do Bento. 
Costumo dizer que para compor suas feições e gestuais, fiz uma "colcha de retalhos" de grandes amores frustrados da minha vida. Para contar essa história do jeito certo, eu precisaria me apaixonar por ela, para que depois doesse muito quando tudo acabasse.

Mario Cau, após olhar uma imagem na sua rede social de uma caricatura sua, me remeteu durante alguns momentos na leitura da obra, uma semelhança ao desenho do personagem Bentinho. Isso foi algo proposital?

Não, eu nunca quis que o Bento tivesse semelhanças comigo. Quis compor o personagem com um visual que fosse algo entre o bonito e o esquisito e que tivesse características próprias, especialmente para diferencia-lo dos outros personagens masculinos, como o Escobar. Mas muitas pessoas me dizem que meus personagens sempre se parecem comigo, mesmo quando eu tento não fazê-lo. Talvez alguns detalhes acabem sendo semelhantes, não sei. Mas não foi intencional.

Em vários momentos na obra, temos a impressão de uma câmera que assim como no cinema usa a técnica do zoom, além dessa outra técnica utilizada nas imagens retira as expressões dos personagens em alguns momentos, e apenas riscos verticais os compõem. Explique um pouquinho sobre o uso dessas técnicas:

Cinema e quadrinhos são duas linguagens com ligações óbvias. Todo meu pensamento de composição de página e, principalmente, de enquadramento para cada quadro, passa por um processo de escolhas. Preciso definir como eu vou registrar cada cena para obter o máximo dos personagens e do texto, sem ser exagerado, sem ser simples demais. Gosto de usar planos variados, gosto de brincar com as prioridades dos planos, de enfatizar pelo intenso ou pelo sublime. Muitas vezes, um personagem que têm os olhos de 
"azeitona" é mais expressivo, para aquele momento, do que um desenhado com todos os detalhes, e omitir certos detalhes faz com que se tenha uma expressividade única. Gosto muito quando o leitor submerge na obra e tenta decifrar cada nuance da arte e do texto, cada escolha feita pelos autores. Tudo está lá por um motivo, para gerar uma reação.

Ter contato com a recriação em quadrinhos de Dom Casmurro é uma experiência diferente do contato com a obra literária, o texto fonte. Afinal, embora tenha o mesmo teor narrativo, trata-se de uma tradução, uma recriação, e não uma cópia de Machado. Como você acha que os leitores encaram isso?

Acho que os leitores, hoje em dia, já estão - ou deveriam estar acostumados com a ideia de que uma adaptação nunca será igual à obra original, pelo simples fato de que a linguagem muda, o suporte muda e os autores que criam a adaptação são outros. Quando se adapta uma HQ para o cinema, ou um vídeo game para livro, ou um poema para o teatro, nunca será possível ser $100 \%$ exato e fiel. Muitas pessoas, fãs ferrenhos da obra original, tecem muitas críticas por adaptações feitas sem profundidade, cuidado ou respeito à obra original, como é o caso de tantos filmes de super-heróis. Existem muitas esferas de interferência nos processos, mas em $\mathrm{HQ}$, geralmente o que existe são os autores e o editor, e no nosso caso, tivemos total liberdade para fazer nossa adaptação e optamos por ser muito fiéis ao texto, sem limites de páginas. É realmente a nossa visão desse clássico, com nossos toques pessoais, ao invés do comumente feito por editoras, que é restringir número de páginas, cores, estilos para que a adaptação se encaixe num padrão de coleção ou comporá governamental.

Recebido em 5 de março de 2017.

Aceito em 23 de maio de 2017. 